\title{
MODIFICAÇÕES QUÍMICAS EM XANTANA PRODUZIDA POR Xanthomonas arboricola pv prUni PROMOVIDAS POR TRATAMENTO TÉRMICO
}

\section{CHEMICAL CHANGES BY THERMAL TREATMENT IN XANTHAN FROM \\ Xanthomonas arboricola pv pruni}

\author{
Carla Ferreira Silveira ${ }^{1}$; Leidi Daiana Preichardt ${ }^{2}$; Angelita da Silveira Moreira ${ }^{3}$; Claire Tondo Vendruscolo ${ }^{4}$ \\ 1,2,3,4 Universidade Federal de Pelotas - UFPel - Pelotas - Brasil \\ carlafesil@hotmail.com
}

\begin{abstract}
Resumo
A xantana é um hidrocolóide produzido por fermentação aeróbia de açúcares a partir de bactérias do gênero Xanthomonas. Suas propriedades reológicas são determinadas pela composição química e massa molar. As condições de produção e pós tratamento fermentativo podem influenciar na composição química e, consequentemente, na viscosidade. O objetivo deste trabalho foi determinar e comparar a composição química e viscosidade de soluções de xantanas produzidas pela cepa EEI de Xanthomonas arboricola pv pruni, em dois diferentes tempos de fermentação (66h e 72h), tratadas e não tratadas termicamente. Neste estudo o tempo de fermentação aumentou o teor de radicais acetil e piruvato, assim como o conteúdo de glicose, enquanto que o tratamento térmico diminuiu estes mesmos parâmetros. Também foi observada a ocorrência de interação entre os fatores conteúdo de açúcares, acetil e piruvato e sua influência na viscosidade dos polímeros.
\end{abstract}

Palavras-chave: modificação química da xantana, acetil, piruvato, açúcares, viscosidade.

\section{Introdução}

A xantana é um hidrocolóide exopolissacarídeo aniônico, produzido industrialmente por fermentação aeróbia de açúcar por culturas de Xanthomonas campestris (LILLY, 1958). Entretanto, as outras espécies de Xanthomonas também são capazes de produzir xantana, com eficiência e qualidade variável (SUTHERLAND, 1982; HAYWARD, 1993; ROTTAVA, 2005; MAYER, 2006). Apesar de possuir custo mais elevado que os polímeros utilizados tradicionalmente, a xantana é o único que apresenta simultaneamente alta viscosidade (elevada capacidade espessante, suspensiva e lubrificante) e pseudoplasticidade (diminuição da viscosidade com o aumento do 
cisalhamento, diminuindo a sensação de gomosidade na boca e facilitando operações de bombeamento, por exemplo) e uma certa tixotropia (recupera rápido, mas não totalmente, a viscosidade do fluído quando cessado o cisalhamento) em baixas concentrações (proporcionando economia); apresenta elevada estabilidade térmica e iônica numa ampla faixa de $\mathrm{pH}$, quando comparada a outros polímeros (COTRELL, 1979; SUTHERLAND, 1982; GARCÍA-OCHOA, 2000); é facilmente biodegradável e não apresenta nenhuma toxicidade (COTRELL, 1980; PARFITT, 1989). Isto torna a xantana um biopolímero de uso múltiplo (MORRIS, 1984).

As propriedades exibidas pela xantana são determinadas por sua composição química (monossacarídeos e derivados e radicais acetil e pirúvico), ligações, arranjo e massa molar. Essas características podem ser alteradas por mudanças na espécie, patovar ou cepa (MORRIS, 1984; SUTHERLAND, 1993; MOREIRA et al. 2001), além das condições de crescimento, como composição do meio (CADMUS et al., 1978; TORRES et al., 1993) e concentração do inóculo (PAN et al., 2000); parâmetros do processo fermentativo como aeração, agitação, temperatura, pH (MORRIS, 1984; GARCÍA-OCHOA, 2000; BORGES et al., 2008a) e tempo de cultivo (VENDRUSCOLO et al., 2000) e ainda tratamentos pós fermentativos (BORGES et al., 2008b). Estas modificações podem promover melhoras no comportamento reológico do polímero e, até mesmo, na estabilidade térmica e compatibilidade deste com sais inorgânicos; estes sais podem ser residuais do processo fermentativo, adicionados intencionalmente ao polímero para melhoria de características como solubilidade, ou fazerem parte da composição do produto onde a xantana será utilizada. A xantana também pode ser modificada através da reação de desacetilação, onde ocorre a remoção dos grupos acetil, presentes na cadeia lateral da molécula (TAKO e NAKAMURA, 1984). Para alguns autores, a desacetilação da xantana possibilita sua interação com outros polissacarídeos, como a goma guar, gerando soluções de viscosidade superior e custo inferior a xantana utilizada isoladamente. Adicionalmente, a mistura polimérica pode ser crosslinkada, resultando em um novo material com maior resistência térmica (SHATWELL e SUTHERLAND, 1990 e 1991).

O objetivo deste trabalho foi determinar e comparar a composição química e viscosidade de soluções de xantanas produzidas pela cepa EEI de Xanthomonas arboricola pv pruni, em dois diferentes tempos de fermentação (66h e 72h), tratadas e não tratadas termicamente.

\section{Material e Métodos}

\subsection{Polímeros utilizados}


Xantanas produzidas por fermentação aeróbia de açúcar pela bactéria Xanthomonas arboricola pv pruni cepa EEI, em $66 \mathrm{~h}$ e $72 \mathrm{~h}$, com e sem tratamento térmico do caldo fermentado centrifugado (E/C e NE/C, respectivamente), segundo Vendruscolo et al., 2006.

\subsection{Determinação de monossacarídeos e derivados}

As xantanas produzidas foram hidrolisadas em tubos fechados com solução de ácido clorídrico $2 \mathrm{~N}$, na proporção de $3: 100(\mathrm{~m} / \mathrm{v})$, em banho-maria a $80^{\circ} \mathrm{C}$ por 16 horas. Após, o produto da hidrólise foi centrifugado a $16000 \mathrm{G}$ durante $5 \mathrm{~min}$ para remoção dos resíduos insolúveis, que foram desprezados.

A determinação dos monossacarídeos e ácido derivado componentes das xantanas foi realizada por cromatografia de camada delgada comparativa (CCDC); os padrões utilizados foram glicose, ramnose, manose e ácido glicurônico. Três $\mu \mathrm{L}$ foram aplicados das amostras hidrolisadas e dos padrões em cromatofolhas de alumínio de silica gel $60 \mathrm{~F}_{254}$ (Merk) e eluidos com clorofórmio:metanol:ácido acético:água na proporção de 40:40:10:10 (v/v/v/v). As cromatofolhas foram reveladas com o reagente anisaldeído sulfúrico, após aquecimento a $100^{\circ} \mathrm{C}$. As bandas foram visualizadas e documentadas com auxilio de scaner hp (MOREIRA et al., 1998).

\subsection{Determinação do grau de acetilação}

A determinação quantitativa de grupos acetil presentes nas amostras de xantana foi realizada através de análise colorimétrica, segundo método preconizado por McComb e McCready (1957). A curva padrão foi elaborada a partir de solução de $\beta$-D-glicose pentacetato em $5 \mathrm{~mL}$ de álcool etílico, a qual teve seu volume completado com água destilada para $100 \mathrm{~mL}$.

Adicionou-se $0,1 \mathrm{~g}$ do biopolímero a $25 \mathrm{~mL}$ de solução de hidroxilamina $3,75 \%(\mathrm{~m} / \mathrm{v})$ e agitado por $15 \mathrm{~min}$. Em seguida, foi acrescentado $25 \mathrm{~mL}$ de solução de hidróxido de sódio 9,4\% $(\mathrm{m} / \mathrm{v})$, esta solução foi agitada até completa dissolução do biopolímero. Uma alíquota de $2 \mathrm{~mL}$ desta solução foi transferida para balão volumétrico de $25 \mathrm{~mL}$, onde foi acrescentado $5 \mathrm{~mL}$ de água, $5 \mathrm{~mL}$ de solução metanólica ácida 70,4\% (v/v); o volume foi completado com solução de perclorato férrico. A concentração de acetil foi determinada através da leitura da absorbância das amostras no comprimento de onda de 520nm em espectrofotômetro (Pharmacia Biotech Ultrospec 2000).

\subsection{Determinação do grau de piruvatação}


A determinação quantitativa de grupos de piruvato nas xantanas foi realizada através de análise colorimétrica, a curva padrão foi elaborada a partir de uma solução de piruvato de sódio $0,1 \mathrm{molL}^{-1}$; para o procedimento, uma solução de $0,4 \%(\mathrm{~m} / \mathrm{v})$ do polissacarídeo foi hidrolisada em ácido clorídrico $2 \mathrm{~N}$ por 3 horas a $90^{\circ} \mathrm{C}$. Uma alíquota de $2 \mathrm{~mL}$ deste hidrolisado reagiu com $1 \mathrm{~mL}$ de 2,4-dinitrofenilhidrazina ( $0,5 \%$ de dinitrofenilhidrazina em uma solução de ácido clorídrico $2 \mathrm{~N})$ por 5 min. A esta mistura foi adicionado $5 \mathrm{~mL}$ de acetato de etila e após, a fase aquosa foi descartada. Em seguida procedeu-se a extração múltipla, acrescentando três porções de $5 \mathrm{~mL}$ de carbonato de sódio $10 \%(\mathrm{~m} / \mathrm{v})$, o extrato de interesse foi diluído a $25 \mathrm{~mL}$ com adição de carbonato de sódio $10 \%$ $(\mathrm{m} / \mathrm{v})$. A concentração de piruvato foi determinada pela medida da absorbância das amostras em 375nm em espectrofotômetro (Pharmacia Biotech Ultrospec 2000) (SLONECKER e ORENTAS, 1962).

\subsection{Reometria}

Foram preparadas soluções aquosas de cada polímero a $0,5 \%$ (p/v) em água deionizada, contendo os conservantes metilparabeno $(0,1 \%)$ e propilparabeno $(0,05 \%)$, e agitadas por $2 \mathrm{~h}$ a temperatura ambiente, mantidas sob banho-maria a $60^{\circ} \mathrm{C}$ por $20 \mathrm{~min}$ (DIAZ, 2002). Após 24h, foram realizadas as leituras em reômetro Haake RS 150, com sistema de cilindros coaxiais e sensor DG 41 , a $25^{\circ} \mathrm{C}$, nas taxas de deformação de $0,01 \mathrm{~s}^{-1}$ a $1000 \mathrm{~s}^{-1}$, durante $300 \mathrm{~s}$

\section{Resultados e Discussão}

\subsection{Açúcares e derivados componentes}

As quatro amostras analisadas possuem em sua composição química manose, glicose, ácido glicurônico e ramnose, conforme o esperado para polímeros produzidos por Xanthomonas arboricola pv pruni (MOREIRA et al., 1998). Os valores de Rf (fator de retenção) para os monossacarídeos glicose, manose e ramnose, no sistema utilizado, foram de 0,61, 0,63 e 0,76, respectivamente, e 0,36 para o ácido glicurônico.

Sloneker e Jeanes (1962) mostraram que a xantana comercial, produzida pela cepa NRLL b1459 De Xanthomonas campestris pv campestris consiste de D-glicose, D-manose, D-ácido glicurônico e resíduos de ácido acético e pirúvico. No entanto, numerosos estudos têm mostrado 
que diferentes cepas de Xanthomonas e condições de cultivo podem produzir polímeros com diferentes composições (SUTHERLAND, 1983). A presença de outros açúcares e ácidos derivados pode facilmente ser detectada pela técnica de cromatografia de camada delgada comparativa. Pequenas diferenças entre os teores destes componentes, entretanto, não podem ser detectadas por esta técnica (MOREIRA et al., 1998; MOREIRA et al., 2001).

Os polímeros produzidos em $72 \mathrm{~h}$ apresentaram maior conteúdo de glicose que aqueles produzidos em 66h, a julgar pelo tamanho e intensidade da coloração das respectivas manchas. Em relação ao tratamento térmico pós-fermentativo, parece ter ocasionado uma redução no conteúdo de glicose em relação ao de manose. A xantana pode sofrer hidrólise parcial durante tratamento térmico (SMITH e PACE, 1982; CALLET et al., 1989; BORGES et al., 2008b), o que pode resultar não só em redução da massa molar (BORGES et al., 2008b ) como em alteração em sua composição química quantitativa (proporção entre os monômeros de açúcares e derivados), o que parece ter ocorrido no presente estudo.

\subsection{Determinação do grau de acetilação e piruvatação}

Os valores de acetil e piruvato das xantanas analisadas estão apresentados na Tabela 1. Os polímeros de $72 \mathrm{~h}$ apresentaram maior teor de acetil e piruvato, em relação aos polímeros de $66 \mathrm{~h}$. $\mathrm{O}$ tratamento térmico ocasionou redução desses valores para ambos; entretanto, isto foi mais acentuado no polímero de $72 \mathrm{~h}$. A redução nos teores de acetil e piruvato ocasionadas pela aplicação de tratamento térmico pós-fermentativo já tem sido relatada na literatura (BORGES et al., 2008b). Entretanto, não há consenso na literatura pertinente sobre o efeito que variações no percentual destes grupos exercem nas propriedades do biopolímero e em suas aplicações (PINTO, 2005). Ao analisarem amostras de xantanas de diferentes cepas de Xanthomonas campestris com diferentes graus de piruvatação, Sandford et al. (1977) deduziram que as xantanas com maior teor de piruvato (4,0-4,8\%) são mais viscosas do que as com menor teor (2,5-3,0\%), particularmente na presença de sais. Xantanas comerciais com diferentes graus de piruvatação, provenientes de diferentes fabricantes, foram examinadas por Smith et al. (1981) estes autores verificaram que um alto teor de piruvato resulta em um aumento na viscosidade quando cloreto de potássio foi adicionado nas soluções isentas de sais. Cheetham e Norma (1989) removeram os grupos piruvato e também verificaram que um alto teor de piruvato resulta em um aumento na viscosidade. Já Tako e Nakamura (1984), ao removerem os grupos acetil de uma amostra de xantana comercial, observaram um incremento da viscoelasticidade do biopolímero desacetilado em altas concentrações em relação ao biopolímero natural. 
Em contrapartida, a xantana comercial proveniente de um único fabricante, preparada com vários teores de acetil e piruvato por Bradshaw et al. (1983), não apresentaram mudança de viscosidade entre si. Soluções de xantana modificadas quimicamente através de remoção parcial dos grupos acetil e piruvato por Callet et al. (1987) também não foram afetadas em suas viscosidades.

Tabela 1. Teores de acetil e piruvato das xantanas com e sem tratamento térmico no caldo fermentado(E=tratamento térmico; $\mathrm{NE}=$ sem tratamento térmico, $\mathrm{C}=$ centrifugado).

\begin{tabular}{lcc}
\hline Amostras & Acetil \% \pm DP & Piruvato \% \pm DP \\
\hline $66 \mathrm{~h} \mathrm{NE} / \mathrm{C}$ & $3,99 \pm 0,02$ & $1,07 \pm 0,09$ \\
$66 \mathrm{~h} \mathrm{E} / \mathrm{C}$ & $2,87 \pm 0,16$ & $0,97 \pm 0,06$ \\
$72 \mathrm{~h} \mathrm{NE} / \mathrm{C}$ & $6,00 \pm 0,26$ & $1,27 \pm 0,10$ \\
$72 \mathrm{~h} \mathrm{E} / \mathrm{C}$ & $4,25 \pm 0,16$ & $1,00 \pm 0,10$ \\
\hline
\end{tabular}

\subsection{Análise reológica}

Os valores de viscosidade das soluções aquosas das xantanas para as respectivas taxas de cisalhamento estão apresentadas na Tabela 2 - taxas de deformação 20, 60, 100 e $1000 \mathrm{~s}^{-1}$ - e demonstrados na Figura 1. Em relação aos polímeros não tratados termicamente, o polímero obtido em $72 \mathrm{~h}$ de fermentação apresentou viscosidade superior. Porém quando submetidos ao tratamento térmico pós-fermentativo, o polímero de 66h apresentou viscosidade levemente superior. Ambos os polímeros tiveram suas viscosidades aumentadas pelo tratamento térmico neste experimento, porem, a influência exercida pelo tratamento térmico sobre a viscosidade dos polímeros é cepa dependente, podendo não aumentar a viscosidade, ou mesmo diminuí-la ${ }^{1}$.

\footnotetext{
${ }^{1}$ Segundo dados experimentais ainda não publicados.
} 
Figura 1. Viscosidade das xantanas ( $\mathrm{E}=$ tratamento térmico; $\mathrm{NE}=$ sem tratamento térmico, $\mathrm{C}=$ centrifugado).

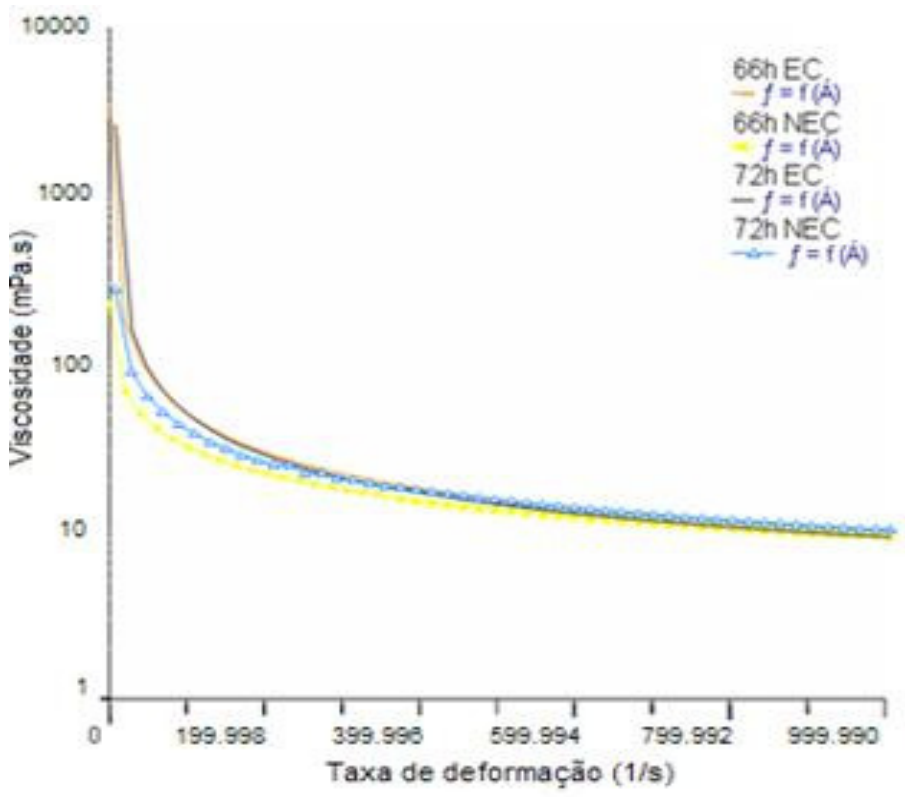

Tabela 2. Viscosidade das xantanas em quatro diferentes taxas de deformação $(\gamma=$ taxa de deformação, $\eta=$ viscosidade).

\begin{tabular}{lcc}
\hline Amostras & $\gamma[1 / \mathrm{s}]$ & $\eta[\mathrm{mPa}]$ \\
66h E/C & 20,25 & 180 \\
& 60,72 & 74,6 \\
& 101,5 & 49,8 \\
& 999,3 & 9,89 \\
66h NE/C & 19,92 & 68,3 \\
& 60,61 & 40,8 \\
& 101,7 & 31,5 \\
& 999,8 & 9,37 \\
72h E/C & 21,42 & 163 \\
& 60,77 & 71,8 \\
& 101,7 & 48 \\
$72 \mathrm{~h} \mathrm{NE} / \mathrm{C}$ & 999 & 9,48 \\
& 21,21 & 92,3 \\
& 61,29 & 53,2 \\
& 102,3 & 39,5 \\
& 999,6 & 10,5 \\
\hline
\end{tabular}

\subsection{Relação entre composição química e viscosidade}

Estudos realizados com xantana aceitam, em geral, a hipótese de que os grupos acetil e piruvato influenciam a viscosidade da xantana. Slonecker e Jeanes (1962) relatam que a remoção dos grupos acetil da xantana sintetizada pela Xanthomonas campestris pv campestris cepa NRRL B1459 proporciona mudanças em suas propriedades físicas, como o incremento de sua viscosidade na presença de sais. Entretanto, em outros estudos, amostras de xantana de diferentes cepas de 
Xanthomonas campestris, com diversos graus de acetilação, apresentaram viscosidades aproximadas (SHATWELL et al., 1990; SUTHERLAND; TAIT, 1992).

No presente trabalho observou-se que os polímeros com maior teor de acetil apresentaram as maiores viscosidades, com exceção do polímero de 66h tratado termicamente; este, apesar de ter o menor percentual de acetil, apresentou a maior viscosidade, porém semelhante ao polímero de $72 \mathrm{~h}$ tratado termicamente. Os polímeros tratados termicamente apresentaram menores teores de piruvato, mas maiores valores de viscosidade, contrariando a teoria predominante de que maiores teores de piruvato resultam em viscosidades mais elevadas. Entretanto, deve-se levar em consideração que o tratamento térmico também ocasionou mudanças no conteúdo de açúcares, aumentando, aparentemente, a proporção de manose em relação a glicose. Segundo Moreira et. al. (2001) polímeros com maior conteúdo de manose apresentam maior valor de viscosidade. Esses resultados indicam a influência da interação entre os fatores conteúdo de açúcares, acetil e piruvato na viscosidade.

\title{
4. Conclusão
}

Os teores de piruvato, acetato e glicose, bem como a viscosidade, das xantanas aumentaram com o tempo de fermentação, enquanto que o tratamento térmico reduziu o conteúdo de piruvato, acetato e glicose e elevou a viscosidade das soluções aquosas das xantanas analisadas. Também foi observada a ocorrência de interação entre os fatores conteúdo de açúcares, acetil e piruvato e sua influência na viscosidade dos polímeros.

\begin{abstract}
The hydrocolloid xanthan is a polysaccharide produced by aerobic fermentation of sugars from bacteria of the genus Xanthomonas. Their rheological properties are determined by the chemical composition and molecular weight. The production conditions and post fermentation treatment may influence the chemical composition and consequently the viscosity. The purpose of this study was to determine and compare the chemical composition and viscosity of solutions of xanthan produced by the strain EEI of Xanthomonas arboricola pv pruni, in two different times of fermentation (66h and $72 \mathrm{~h}$ ), thermally treated and untreated. In this study the time of fermentation increased the content of radicals acetyl and pyruvate, and the contents of glucose, while the heat treatment decreased these parameters. It was also observed the occurrence of interaction between the factors sugars, acetyl and pyruvate content and its effect on the viscosity of the polymers.
\end{abstract}

Key-words: chemical changes in xanthan, acetyl, pyruvate, carbohydrates, viscosity.

\section{Referências}

BORGES, C. D.; MOREIRA, A. DA S.; VENDRUSCOLO, C. T.; AYUB, M. A. Influence of agitation and aeration in xanthan production by Xanthomonas campestris pv pruni strain 101, Revista Argentina de Microbiología, v. 40, p. 81-85, 2008a. 
BORGES, C. D.; MOREIRA, A. DA S.; VENDRUSCOLO, C. T.; AYUB, M. The influence of thermal treatment and operatioanal conditions on xanthan produced by $X$. arboricola pv pruni strain 106, Carbohydrate Polymers (2008b), doi:10.1016/j.carbpol.2008.07.013.

BRADSHAW, I. J.; NISBET, B. A.; KERR, M. H.; SUTHERLAND, I. W. Modified xanthan-its preparation and viscosity, Carbohydrate Polymers, v. 3, p. 23-38, 1983.

CADMus, M. C.; KNUTSOn, C. A.; LAgOdA, A. A.; PITTSlEY, J. E.; BUSTON, K. A. Synthetic media for production of quality xanthan gum in 20 liter fermentors. Biotechnology and Bioengineering, v. 20, p. 1003-1014, 1978 .

CALLET, F.; MILAS, M.; RINAUDO, M. Influence of acetyl and pyruvate contents on rheological properties of xanthan in dilute solution. International Journal Biological Macromolecules, v. 9, p. 291-293, 1987.

CALLET, F.; MILAS, M.; RINAUDO, M. On the role of thermal treatments on the properties of xanthan solutions. Carbohydrate Polymers, v. 11, p. 127-137, 1989.

CHEETHAM, N. W. H.; NORMA, N. M. N. The effect of pyruvate on viscosity properties of xanthan. Carbohydrate Polymers, v. 10, p. 55-60, 1989.

DIAZ, P. S. Influência de parâmetros físicos e químicos e da adição de íons no comprotamento reológico de gomas xantana. Dissertação (Programa de Pós-Graduação em Ciência e Tecnologia Agroindustrial), Faculdade de Agronomia Eliseu Maciel, Universidade Federal de Pelotas, 2002.

COTTRELL, I. W. In: P. A. Sandford; K. Matsuda. American Chemical Society, New York, 251-270 (ACS Symposium Series), 1979.

GARCÍA-OCHOA, F.; SANTOS, V. E.; CASAS, J. A.; GÓMEZ, E. Xanthan gum: production, recovery and properties, Biotechnology Advances, n. 7, v. 18, p. 549-579, 2000.

HAYWARD, A. C. The hosts of Xanthomonas. In: SWINGS, J. G., CIVEROLO, E. L. Xanthomonas. London: Chapman \& Hall, 1993. p.1.

LILLY, V. G.; WILSON, H. A.; LEARCH, J. G. Bacterial polysaccharides II. Laboratory Scale production of polysaccharides by species X. campestris, Applied Microbiology and Biotechnology, v. 6, p. 105-109, 1958.

MAYER, L.; BORGES, C. D.; VENDRUSCOLO, C. T. Produção de biopolimero xantana por cepas de Xanthomonas axonopodis patovar phaseoli. In: XX CBCTA, 2006.

McCOMB, E. A.; McCREADY, R. M. Determination of acetyl in pectin and in acetylated carbohydrate polymers, Analytical Chemistry, n. 5, v. 29, p. 819-821, 1957.

MOREIRA, A.S.; SOUZA, A.S.; VENDRUSCOLO, C.T. Determinação da composição de biopolímero por cromatografia em camada delgada: metodologia. Revista Brasileira de Agrociência, v. 3, p. 222-224, 1998.

MOREIRA, A. S.; VENDRUSCOLO, J. L. S.; GIL-TURNES, C.; VENDRUSCOLO, C. T. Screening among 18 novel strains of Xanthomonas campestris pv pruni. Food Hydrocolloids, v. 15, p. 469-474, 2001.

MORRIS, E.R. Rheology of hydrocolloids. In: G.O. PHILLIPS, D. J. \& WEDLOCK, P. A. WILLIAMS. Gums and stabilisers for the food industry Oxford: Pergamon Press, p. 57-78, 1984.

PAN, A.; MOREIRA, A. da S.; VENDRUSCOLO, C. T. Efeito da concentração inicial do inoculo no crescimento celular e quantidade de biopolímeros de Xanthomonas campestris pv pruni cepa 06. Revista Brasileira de Agrociência, v. 6, p. 273-277.

PINTO, E. P. Desacetilação de xantana: influência no comportamento reológico. Dissertação (Programa de PósGraduação em Ciência e Tecnologia Agroindustrial), Faculdade de Agronomia Eliseu Maciel, Universidade Federal de Pelotas, 2005.

PARFITT, K. Ed. Stabilising and suspending agents. In Martindale: The complete drug reference. 32 ed. London: Pharmaceutical Press, p. 1470, 1999. 
ROtTAVA, I.; BATESINI, G. ; CANSIAN, R. L. ; ANTUNES, O. A. C. ; PADILHA, F. F. Seleção de linhagens de Xantohomonas sp para produção de goma xantana. In: Sinaferm 2007 - XVI Simpósio Nacional de Bioprocessos, Curitiba-PR. Sinaferm 2007.

SANDFORD, P. A.; PITTSLEY, J. E.; KNUTSON, C. A.; WATSON, P. R.; CADMUS, M.C.; JEANE, A. Variation in Xanthomonas campestris NRRL B-1459: characterization of xanthan products of differing strains. In: SANDFORD, P. A.; LASKINS, A. Extracellular Microbial Polysaccharides. Washington, D. C.: American Chemical Society, p. 192$210,1977$.

SHATWELL, K. P.; SUTHERLAND, I. W.Influence of acetyl and pyruvate substituents on the xanthan with plant polyssaccharides - I. Xanthan - Locus bean gum system. Carbohydrate Polymers, v. 14, p. 29-51, 1991.

SHATWELL, K. P.; SUTHERLAND, I. W.; DEA, I. C. M.; ROSS-MURPHY, S. B. The influence of acetyl and pyruvate substituents on the helix-coil transition behavior of xanthan. Carbohydrate Polymers, v. 206, p. 87-103, 1990.

SMITH, I. H.; PACE, G. W. Recovery of microbial polysaccharides. Journal of Chemical Tecnology and Biotechnology, v. 32, p. 119-129, 1982.

SMITH, I. H.; SYMES, K. C.; LAWSON, C. J.; MORRIS, E. R. Influence of the pyruvate of xanthan on macromolecular association in solution. International Journal of Biological Macromolecules, v. 3, p. 129-134, 1981.

SLONEKER, J. H.; JEANES, A. Exocellular bacterial polysaccharide from Xanthomonas campestris NRRL B - 1459. Canadian Journal of Chemistry, n. 11, v. 40, p. 2066-2071, 1962.

SUTHERLAND, I. W. Biosynthesis of microbial exopolysaccharides. Advances Microbial Physiology, v. 23, p. 80$142,1982$.

SUTHERLAND, I.W.; TAIT, M.I. Biopolymers. Encyclopedia of Microbiology, v. 1, p. 339-349, 1992.

SUTHERLAND, I. W. Extracellular polysaccharide. In: Dellweg, H. Biotechnology Weinheim: Verlag Chemie, v. 3, p. 531-574, 1983.

TAKO, M.; NAKAMURA, S. Rheological properties of deacetylated xanthan in aqueous media. Agricultural and Biological Chemistry, n. 12, v. 48, p. 2887-2993, 1984.

TORRES, L. G.; BRITO, E.; GALINDO, E.; CHOPIN, L. Viscous behaviour of xanthan áqüeos solution from a variant of Xanthomonas campestris. Journal of Fermentation and Bioengineering, v. 75, p. 58-64, 1993.

VENDRUSCOLO, C. T.; MOREIRA, A. da S.; SOUZA, A. da S.; ZAMBIAZI, R.; SCAMPARINI, A. R. P. Heteropolysaccharide produced by Xanthomonas campestris pv pruni C 24. In: Nishinari, K. Hydrocolloids. Amsterdam: Elsevier., v.1, p. 187-191, 2000.

VENDRUSCOLO, C. T.; MOREIRA, A. da S.; VENDRUSCOLO, J. L. Process for preparing a xanthan biopolymer. Int. WO/2006/047845. 2006.

Nome completo: Carla Ferreira Silveira

Filiação institucional: Universidade Federal de Pelotas

Departamento: Centro de Biotecnologia

Função ou cargo ocupado: Mestranda

Titulação: Bacharel em Química

Endereço completo para correspondência: Campus Universitário, s/n ${ }^{\circ}$ Pelotas, RS/Brasil • Caixa

Postal 354 - CEP: 96010-900.

Telefones para contato: +555332757585

e-mail:carlafesil@hotmail.com 